\title{
An Integration of Major Coffee Consuming Centres in India - An Economic Analysis
}

\author{
M. Balakrishnan* and K. Chandran \\ Department of Agricultural Economics, Tamil Nadu Agricultural University, Coimbatore, \\ Tamil Nadu - 641 003, India \\ *Corresponding author
}

\section{Keywords}

Coffee, Agricultural commodities,

Economic analysis

Article Info

Accepted:

10 February 2018

Available Online:

10 March 2018

\section{A B S T R A C T}

The price signals of agricultural commodities from markets located in different locations play a very important role in the economy. The price signals guide and regulate production, consumption and marketing decisions over time. Therefore, if markets are not well integrated, the price signals are distorted, which will lead to inefficient resource allocation and hamper sustainable agricultural development. This paper employs an econometric modeling for estimating a vector error correction model (VECM) to investigate the degree of spatial market integration and price transmission between the important coffee consuming centers in India (viz. Bangalore, Chennai and Hyderabad) using month-wise wholesale prices of coffee seeds. The bidirectional causality among the monthly Wholesale Prices of Rs $/ \mathrm{kg}$ of clean coffee seeds of Arabica Parchement variety in Bangalore and Chennai markets. There was a long-run co integration relationship between Hyderabad consuming centre and Bangalore consuming centre with other consuming centre as the co integration coefficient for these consuming centres are Positive and significant at one per cent level. Similarly, it was found that a long-run co integration relationship between Bangalore consuming centre with other consuming centres as the co integration coefficient for Bangalore consuming centre is Positive and significant at one per cent level.

\section{Introduction}

Coffee production in India grew rapidly in the 1950 s, increasing from 18,893 tonnes in 1950 51 to 68,169 tonnes in 1960-61. Growth in India's coffee industry, however, has been especially robust in the post-liberalisation era, backed by the government's decision to allow coffee planters to market their own produce, rather than selling to a central pool. Coffee production in India stood at 348,000 metric tonnes (MT) in 2015-16. Robusta variety accounted for 244,500 MT (70.3 per cent) of this production, while Arabica accounted for 103,500 MT (29.7 per cent). The post-blossom estimate for $2016-17$ is 320,000 MT $(100,000$ MT of Arabica and 220,000 MT of Robusta) India has emerged as the seventh largest coffee producer globally; after Brazil, Vietnam, Columbia, Indonesia, Ethiopia and Honduras. It accounted for 2 per cent of the area under production and 3.7 per cent of the 
production in 2012 as compared to 3.18 per cent of production in 1992-93. In 2015-16, India accounted for $4.05 \%$ of global coffee production.

Coffee is grown in three regions of India with Karnataka, Kerala and Tamil Nadu forming the traditional coffee growing region of India, followed by the new areas developed in the non-traditional areas of Andhra Pradesh and Orissa in the eastern coast of the country and with a third region comprising the states of Assam, Manipur, Meghalaya, Mizoram, Tripura, Nagaland and Arunachal Pradesh of Northeastern India, popularly known as "Seven Sister States of India".

The area under coffee plantations in India has increased by more than three times, from 120.32 thousand hectares in 1960-61 to 397.147 thousand hectares in 2015-16. Most of this area is concentrated in the southern states of Karnataka (54.95\%), Kerala $(21.33 \%)$ and Tamil Nadu (8.18\%). Productivity has also improved from around $567 \mathrm{~kg} / \mathrm{Ha}$ in 1961 to around $876 \mathrm{~kg} / \mathrm{Ha}$ during 2015-16. For the traditional areas, productivity has grown from $412 \mathrm{~kg} / \mathrm{Ha}$ in 1961 to $1,008 \mathrm{~kg} / \mathrm{Ha}$ in $2015-16$. The industry is driven by the enterprise of around 280,241 coffee growers, out of which $99 \%$ are small growers, while $1 \%$ are medium to large growers. These plantations employ an average of around 632,993 people on a daily basis, as per estimates for 2015-16. There are approximately 250,000 coffee growers in India; 98 per cent of them are small growers. Over 90 percent of them are small farms consisting of 10 acres (4.0 ha) or fewer. According to published statistics for 20012002 , the total area under coffee in India was 346,995 hectares $(857,440$ acres) with small holdings of 175,475 accounting for 71.2 per cent. The area under large holding of more than 100 hectares (250 acres) was 31,571 hectares $(78,010$ acres) (only 9.1 per cent of all holdings) only under 167 holdings. The area under less than 2 hectares (4.9 acres) holdings was 114,546 hectares $(283,050$ acres) (33 per cent of the total area) among 138,209 holders. Among the states, the final estimate for Karnataka is placed at 221,745 MT comprising of 70,510 MT of Arabica and 151,235 MT of Robusta, recording a decline of 4,555 MT (-2.01per cent) over the postmonsoon estimate of 2016-17. The production of Arabica has declined by 1,090 MT (1.52per cent) and Robusta declined by 3,465 MT (-2.24per cent) over the post monsoon estimate. Among the districts, the major loss of about 4,290 MT is reported from Kodagu district. In Kerala, the final estimate of 201617 is placed at 63,265 MT with a marginal decline of 25 MT (-0.04per cent) over the post monsoon estimate $(63,290$ MT) of 201617.The Tamil Nadu, the final production of 2016-17 is placed at 16,335 MT which is a marginal decline of 225 MT (-1.36per cent) over the post monsoon estimate (16,560 MT) of 2016-17.

Coffee is world famous beverage and is widely drunk almost every part of the world. This drink is made from coffee seeds which are also referred to as "beans". The total coffee production in the world is around six million tons and India share $4.5 \%$ of total production in the world. Coffee production in India is mainly concentrated in the southern part of the country in which Karnataka is the leading coffee producer followed by Kerala and Tamil Nadu. Almost $80 \%$ of country's coffee production is exported to different country. In our country, mainly two types of coffee varieties are cultivated. Robusta coffee or Coffearobusta is grown around 52\% of total coffee area and arabica coffee or Coffeaarabica is grown around $48 \%$ of the total coffee area. Considering the sustainable source of foreign exchange earnings to Indian economy, it is therefore important to analyze countries major coffee marketing system so 
that countries coffee production as well as export is efficiently managed. Presence of perfect market integration and price transmission are very important phenomenon to be considered for efficient management of marketing system. In an efficient marketing system, new information is confounded simultaneously into markets when they are cointegrated. This type of system has a considerable significance for deriving maximum gains for producers, consumers and middleman in the marketing chain. Currently financial markets are characterized by increasing volatility. Commodity market or the coffee market is prone to abrupt movements (Huchet, 2011). Increased variability in prices occurs in these markets, particularly in the "post-crisis" period (Engle et al., 2013). Commodity markets play an important role in the global financial system (Irwin, S.H., P. Garcia, D.L. Good, and E.L. Kunda, 2008). This paper has highlighted the degree of market integration among major coffee centers in India such as Bangalore, Chennai and Hyderabad. The nature of cointegration and extent of price adjustment for different markets has been evaluated. Depending on the market structure, the direction of price transmission among different markets has been investigated as it provides valuable information on the degree of integration and efficiency of markets. Finally an effort is made for forecasting the performance of spatially separated markets.

\section{Data sources and methodology}

For the present study, the time series data on monthly Wholesale Prices of Rs $/ \mathrm{kg}$ of clean coffee seeds of Arabica Parchement variety in major Consuming Centres viz., Chennai, Bangalore and Hyderabad prices of coffee (Jan 2009 to November 2017) are sourced from coffee board. The ultimate aim of present study is to examine the empirical relationship between the prices among the markets. The problem with approaching time series data is the problem of non stationarity. Before analyzing any time series data, testing for stationarity is a prerequisite since econometric relation between the time series has the presence of trend components. This involved testing for stationarity of the variables using Augmented Dickey Fuller (ADF) test. The ADF tests mentioned above consider the null hypothesis that a given series has a unit root, i.e., it is non stationary. The test is applied by running the regression of the following form:

$$
\Delta Y_{t}=\beta_{1}+\delta Y_{t-1}+\alpha_{i} \sum \Delta Y_{t-1}+e_{t}
$$

If the coefficient $\delta$ is not statistically different from zero, it implies that the series have a unit root, and, therefore, the series is nonstationary. To verify that the first differenced price series are indeed stationary, Augmented Dickey-Fuller (ADF) unit root tests are used. The null hypothesis of non - stationary is tested using a t-test.

The null hypothesis is rejected if estimated variable is significantly negative. For testing stationarity in the above equation, $Y_{i}$ denoted the Wholesale Prices of Rs/kg of clean coffee seeds of arabicaparchement variety in major Consuming Centres viz., Chennai, Bangalore and Hyderabad prices of coffee (Jan 2009 to November 2017). $i=1,2$ and 3 (1-Chennai; 2Bangalore and 3 - Hyderabad [t-1: 1 month lagged price and $\Delta$ : differenced series] (Note: CBPL, CHPL and CHPL - Wholesale Prices of $\mathrm{Rs} / \mathrm{kg}$ of clean coffee seeds of arabicaparchement variety).

Once the variables are checked for stationarity and are of the same order, integration between them can be tested using methods such as Augmented Dickey Fuller Test or Johansen Maximum Likelihood Test in a bivariate as well as multivariate framework. If the estimated value of error term exceeds critical values at one percent, five percent and 10 percent levels of significance, the conclusion 
would be that the residual term is stationary and hence the two individual series, through non-stationary, are co-integrated in the long run.

The Granger test is based on a premise that if forecasts of some variable, say $X$, obtained by using both the past values of $X$ and the past values of another variable $Y$, is better than the forecasts obtained using past values of $X$ alone, $Y$ is then said to cause $X$. The model proposed by Granger was:

$$
\begin{aligned}
& Y_{i}=a_{i} Y_{t-i}+b_{i} X_{t-i}+e_{i} \\
& X_{i}=c_{i} Y_{t-i}+d_{i} X_{t-i}+v_{i}
\end{aligned}
$$

Where, $X_{i}$ and $Y_{i}$ are two stationary time series with zero mean: $e_{i}$ and $v_{i}$ are two uncorrelated series, lag length is assumed to be finite and shorter than the time series considered. Since the series of the variable are usually non-stationary and integrated of order I (1), first difference of the variable is normally taken which is stationary. The optimal lag length of the variables is determined by minimizing Akaike's Information Criterion. Based on equations 1 and 2, unidirectional causation from one variable $X$ to $Y$ (i.e. $X$ Granger causes $Y$ ) is observed if the estimated coefficient on the lagged $X$ variable in equation (1) is statistically non-zero as a group and the set of lagged $Y$ coefficient is zero in equation (2). Similarly, unidirectional causation from $Y$ to $X$ (i.e. $Y$ Granger causes $X$ ) is implied if the estimated coefficient on the lagged $Y$ in equation (2) are statistically different from zero as a group and the set of estimated coefficient on the lagged $X$ variable in equation (1) is not statistically different from zero. Feedback or mutual causality (bidirectional) would occur when the set of coefficients on the lagged $X$ variable in equation (1) and on lagged variable $Y$ in equation (2) are statistically different from zero. Finally, independence exists when the coefficients of both $X$ and $Y$ variables are equal to zero. For the proposed study, $X_{i}$ and $Y_{i}$ denoted the Wholesale Prices of Rs/kg of clean coffee seeds of Arabica Parchement variety in major Consuming Centres viz., Chennai, Bangalore and Hyderabad (Note: CBPL, CHPL and CHPL - Wholesale Prices of $\mathrm{Rs} / \mathrm{kg}$ of clean coffee seeds of Arabica Parchement).

An Error Correction Model (ECM) is a neat way of combining the long run, co integrating relationship between the levels variables and the short run relationship between the first differences of the variables. It has also had the advantage that all the variables in the estimated equation are stationary, hence there is no problem of spurious correlation. Engel and Granger (1987) demonstrated that once a number of variables are found to be co integrated, then there existed a corresponding error correction representation which implied that the changes in the dependent variable are a function of the level of disequilibrium in the co integrating relationship as well as changes in other variables. If the price series are I (1), then one could run regressions in their first differences. However, by taking first differences, we lose the long run relationship that is stored in the data which implied use of variables in levels as well. Advantage of error correction methodology is that it incorporates variables both in their levels and first differences. By doing this, ECM captures the short run equilibrium situations as well as the long run equilibrium adjustments between prices.

Even if one demonstrates market integration through co integration, there could be disequilibrium in the short run, i.e., price adjustment across markets may not happen 
instantaneously. It may take some time for the spatial price adjustments. ECM can incorporate such short run and long run changes in the price movements.

A generalized ECM formulation to understand both the short run and long run behaviour of prices can be considered by the first taking the Autoregressive Distributed Lag (ADL) equation as follows:

$$
Y_{t}=a_{01} X_{t}+a_{11} X_{t-1}+a_{12} Y_{t-1}+\varepsilon_{t}
$$

By adding and deleting $Y_{t-1}, a_{01} X_{t-1}$, rearranging terms, and using the difference equator, the above equation can be written in the ECM format as follows:

$$
\Delta Y_{t}=a_{01} \Delta X_{t}+\left(1-a_{12}\right)\left[\frac{\left(a_{01}+a_{11}\right)}{\left(1-a_{12}\right)} X_{t-1}-Y_{t-1}\right]+\varepsilon_{t}
$$

The generalized form of this equation for $\mathrm{k}$ lags and an intercept term is as follows:

$\Delta Y_{t}=a_{00}+\sum_{i=0}^{k-1} a_{i 1} \Delta X_{t-1}+\sum_{i=1}^{k-1} a_{i 2} \Delta Y_{t-1}+m_{0}\left[m_{1} X_{t-k}-Y_{t-k}\right]+\varepsilon_{t}$

Where, $m_{0}=\left(1-\sum_{i=1}^{k} a_{i 2}\right)$, and $m_{1}=\frac{\sum_{i=0}^{k} a_{i 1}}{m_{0}}$.

If all the variables are I(1), i.e., they are integrated of order 1 , they are stationary in first difference. Therefore, all the summations in the above equations are also stationary. Moreover, if the variables are cointegrated, the ECM term, i.e., the linear combination of variables represented in parentheses is also stationary. The $a_{i j}$ coefficients capture the short run effects and $m_{j}$ coefficients represent the stationary long run impacts of the right hand side variables. The parameter $m_{0}$ measures the rate of adjustment of the short run deviations towards the long run equilibrium. Theoretically, this parameter lies between 0 and 1 . The value 0 denotes no adjustment and 1 indicates an instantaneous adjustment. A value between 0 and 1 indicates that any deviations will have gradual adjustment to the long run equilibrium values.

So the Vector Error Correction Mechanism is used to distinguish short term from long term association of the variables included in the model. When the variables are not integrated, then in the short term deviation from this longterm equilibrium would feed back to the changes in the dependent variable in order to force the movement according to the long run equilibrium relationship. The long term causal relationship among the future markets is implied through the significance of ' $t$ ' tests of the lagged error correction term as it contains the long term information because it is derived from the long term relationship. The coefficient of the lagged error correction term is a short-term adjustment coefficient and represented the proportion by which the commodity futures adjusted with exchange rate to respond to the long run disequilibrium.

\section{Results and Discussion}

To verify level and first differenced price series were indeed stationary, Augmented Dickey-Fuller (ADF) unit root test was used. The ADF test results are presented for the period Jan 2009 to November 2017. The equations were estimated with an intercept and time trend.

The results are presented in Table 1 for Augmented Dickey-Fuller (ADF) unit root tests for each series. The null hypothesis of non - stationarity was tested based on the critical values reported by MacKinnon. 
Table.1 Results of unit root test (ADF test)

\begin{tabular}{|c|c|c|c|c|}
\hline Variable & Level & Lags & First difference & Lags \\
\hline CBPL & -2.6062 & $(1)$ & $-7.8554^{* * * *}$ & $(0)$ \\
\hline CHPL & -2.6644 & $(1)$ & $-11.2453 * * *$ & $(0)$ \\
\hline CCPL & -2.8758 & $(1)$ & $-9.3619 * * * *$ & $(0)$ \\
\hline
\end{tabular}

\{Note: Figures in parentheses are the number of significant lags

*** Significant at 1 percent level

CBPL, CHPL \& CCPL - monthly Wholesale Prices of Rs $/ \mathrm{kg}$ of clean coffee seeds of Arabica Parchement variety in major Consuming Centres viz., Chennai, Bangalore and Hyderabad

Table.2 Results of causality test

\begin{tabular}{|c|c|c|}
\hline Null hypothesis & F - statistic & P -value \\
\hline HPL does not Granger Cause BPL & 0.66001 & 0.5191 \\
\hline BPL does not Granger Cause HPL & 13.8600 & 5.E-06 \\
\hline CPL does not Granger Cause BPL & 2.84181 & 0.0630 \\
\hline BPL does not Granger Cause CPL & 8.80832 & 0.0003 \\
\hline CPL does not Granger Cause HPL & 1.96810 & 0.1451 \\
\hline HPL does not Granger Cause CPL & 3.96886 & 0.0219 \\
\hline \multicolumn{3}{|c|}{$\begin{array}{l}\text { ** Significant at } 5 \text { percent level, * significant at } 10 \text { percent level, NS - Not significant } \\
\text { The test for causality is based on F statistics that is calculated by using unconstrained and constrained forms, } \\
\left.\mathrm{F}=\left\{\mathrm{SSE}_{\mathrm{r}}+\mathrm{SSE}_{\mathrm{f}}\right) / \mathrm{m}\right\} /\left\{\mathrm{SSE}_{\mathrm{f}} /(\mathrm{T}-2 \mathrm{~m}-1)\right\} \\
\text { Where } \mathrm{SSE}_{\mathrm{r}} \text { and } \mathrm{SSE} \mathrm{f}_{\mathrm{f}} \text { are residual sum of squares of the reduced and full models respectively; } \mathrm{T}=\text { total number of } \\
\text { observations, and } \mathrm{m}=\text { number of lags. } \\
\text { \{CBPL, CHPL \& CCPL - monthly Wholesale Prices of Rs/kg of clean coffee seeds of Arabica Parchement variety } \\
\text { in major Consuming Centres viz., Chennai, Bangalore and Hyderabad }\}\end{array}$} \\
\hline
\end{tabular}

Table.3 Results of multiple co-integration tests

\section{Trace statistics of Series BPL, HPL \& CPL}

\begin{tabular}{|c|c|c|c|c|}
\hline No. of CE(s) & Eigenvalue & Statistic & Critical value & Probability \\
\hline None & 0.25413 & $37.7578 * * *$ & 24.2759 & 0.0006 \\
\hline At most 1 & 0.0708 & 7.8500 & 12.3209 & 0.2485 \\
\hline At most 2 & 0.0034 & 0.3557 & 4.1299 & 0.6137 \\
\hline
\end{tabular}

Critical values based on MacKinnon (1991). LR test indicated 1 co-integrating equation significant at 5 per cent level.

\{Note: \{CBPL, CHPL \& CCPL - monthly Wholesale Prices of Rs $/ \mathrm{kg}$ of clean coffee seeds of Arabica Parchement variety in major Consuming Centres viz., Chennai, Bangalore and Hyderabad\} 
Table.4 Reduced form vector error correction estimates

\begin{tabular}{|c|c|c|c|}
\hline Error Correction & D(HPL) & D(CPL) & D(BPL) \\
\hline \multirow[t]{3}{*}{ ECM } & -0.010653 & 0.497362 & 0.137055 \\
\hline & $(0.09337)$ & $(0.11577)$ & $(0.07766)$ \\
\hline & {$[-0.11410]$} & [ 4.29626] & [ 1.76485$]$ \\
\hline \multirow[t]{3}{*}{ D(HPL(-1)) } & -0.407491 & -0.231858 & -0.198259 \\
\hline & $(0.13669)$ & $(0.16948)$ & $(0.11369)$ \\
\hline & [-2.98104] & {$[-1.36804]$} & {$[-1.74385]$} \\
\hline \multirow[t]{3}{*}{ D(HPL(-2)) } & -0.182958 & -0.262803 & -0.166862 \\
\hline & $(0.12790)$ & $(0.15857)$ & $(0.10637)$ \\
\hline & {$[-1.43052]$} & {$[-1.65730]$} & {$[-1.56865]$} \\
\hline \multirow[t]{3}{*}{ D(CPL(-1)) } & -0.047653 & 0.319134 & 0.283957 \\
\hline & $(0.11782)$ & $(0.14608)$ & $(0.09799)$ \\
\hline & {$[-0.40446]$} & [ 2.18466] & [ 2.89775] \\
\hline \multirow[t]{3}{*}{ D(CPL(-2)) } & 0.004418 & 0.133460 & 0.116563 \\
\hline & $(0.11718)$ & $(0.14529)$ & $(0.09746)$ \\
\hline & [ 0.03771$]$ & [ 0.91858$]$ & [ 1.19598] \\
\hline \multirow[t]{3}{*}{ D(BPL(-1)) } & 0.550923 & 0.251740 & 0.116158 \\
\hline & $(0.15109)$ & $(0.18732)$ & $(0.12566)$ \\
\hline & [ 3.64643] & [ 1.34387$]$ & [ 0.92438] \\
\hline \multirow[t]{3}{*}{ D(BPL(-2)) } & 0.377128 & 0.222136 & 0.177578 \\
\hline & $(0.15304)$ & $(0.18975)$ & $(0.12729)$ \\
\hline & [ 2.46417] & [ 1.17066$]$ & [ 1.39507$]$ \\
\hline c & 1.1250 & 0.7311 & 0.2491 \\
\hline R-squared & 0.208313 & 0.226377 & 0.151861 \\
\hline Adj.R-squared & 0.150586 & 0.169967 & 0.090018 \\
\hline AIC & 8.538042 & 8.968039 & 8.169515 \\
\hline
\end{tabular}

Note: Bold and italics are the significant variables

\{CBPL, CHPL \& CCPL - monthly Wholesale Prices of Rs $/ \mathrm{kg}$ of clean coffee seeds of Arabica Parchement variety in major Consuming Centres viz., Chennai, Bangalore and Hyderabad\}

All the price series appeared non stationary in the levels, but all the series were stationary after taking first differences. After confirming the currency exchange rates were stationary in their first differences, co integration between the commodity futures was tested using Johansen's maximum likelihood procedure.

The bivariate co integration technique of Engle and Granger was also tested for the presence of long run relationship existing between the monthly Wholesale Prices of $\mathrm{Rs} / \mathrm{kg}$ of clean coffee seeds of Arabica Parchement variety in major Consuming Centres viz., Chennai, Bangalore and Hyderabad.
The causal relationship between the exchange rates of monthly Wholesale Prices of Rs $/ \mathrm{kg}$ of clean coffee seeds of Arabica Parchement variety in major Consuming Centres were approached through Granger's Causality technique presented in Table 2 . It could be seen that existence of unidirectional causality among the monthly Wholesale Prices of Rs/kg of clean coffee seeds of Arabica Parchement variety in major Consuming Centres viz., Chennai, Bangalore and Hyderabad exerted mutual influence upon each other during the investigation period. 
The bidirectional causality among the monthly Wholesale Prices of Rs $/ \mathrm{kg}$ of clean coffee seeds of Arabica Parchement variety in Bangalore and Chennai markets.

Results of co-integration analysis of presented in Table 3 revealed that there were one cointegrating vectors among them, which proved that there was a long run relationship among the monthly Wholesale Prices of Rs/kg of clean coffee seeds of Arabica Parchement variety in major Consuming Centres viz., Chennai, Bangalore and Hyderabad.

\section{Vector error correction estimates}

To know the short run adjustment between the selected markets, VECM was computed and the results are presented in Table 4. The estimates of error correction coefficients confirmed that the Tamil Nadu Chennai market came to equilibrium under short run when compared to other markets. The speed of adjustment for short run equilibrium by the Tamil Nadu market was rapid as seen from the error correction equation. But under long run, the major consuming centres were influenced by their own lag as well as lag price of other markets in India. There was a long-run co integration relationship between Hyderabad consuming centre and Bangalore consuming centre with other consuming centre as the co integration coefficient for these consuming centres are Positive and significant at one per cent level. Similarly, it was found that a long-run co integration relationship between Bangalore consuming centre with other consuming centres as the co integration coefficient for Bangalore consuming centre is Positive and significant at one per cent level.
From all the above results, it is concluded that the existence of unidirectional causality among the monthly Wholesale Prices of Rs/kg of clean coffee seeds of Arabica Parchement variety in major Consuming Centres viz., Chennai, Bangalore and Hyderabad exerted mutual influence upon each other during the investigation period. The bidirectional causality among the monthly Wholesale Prices of Rs/kg of clean coffee seeds of Arabica Parchement variety in Bangalore and Chennai markets. There was a long-run co integration relationship between Hyderabad consuming centre and Bangalore consuming centre with other consuming centre as the co integration coefficient for these consuming centres are Positive and significant at one per cent level. Similarly, it was found that a long-run co integration relationship between Bangalore consuming centre with other consuming centres as the co integration coefficient for Bangalore consuming centre is Positive and significant at one per cent level.

\section{References}

Engle, Robert F. A W. J. Granger. CoIntegration and Error Correction: Representation, Estimation, and Testing. Econometrica. 1987

Huchet-Bourdon, M. (2011). Agricultural Commodity Price Volatility: An Overview“, OECD Food, Agriculture and Fisheries Papers, No. 52, OECD Publishing.

Irwin, S.H., P. Garcia, D.L. Good, and E.L. Kunda. "Recent Convergence Performance of CBOT Corn, Soybean, and Wheat Futures Contracts." Choices, 2nd Quarter, 23(2008):16-21.

\section{How to cite this article:}

Balakrishnan, M. and Chandran, K. 2018. An Integration of Major Coffee Consuming Centres in India - An Economic Analysis. Int.J.Curr.Microbiol.App.Sci. 7(03): 1090-1097. doi: https://doi.org/10.20546/ijcmas.2018.703.130 